\title{
Atitudes de enfermeiros de hospital geral frente às características pessoais do paciente alcoolista
}

\author{
Attitudes of clinical nurses toward personal characteristics of alcoholics patients
}

Actitudes de enfermeros de hospital general frente a las caracteristicas personales de pacientes alcohólicos

\section{Divane de Vargas ${ }^{1}$}

'Universidade de São Paulo. Escola de Enfermagem. São Paulo, SP

Submissão: 28/12/2008

Aprovação: 23/05/2010

\section{RESUMO}

Estudo exploratório que objetivou verificar as atitudes de enfermeiros de hospital geral frente às características pessoais de alcoolista. Na coleta de dados, utilizou-se a subescala IV da Seamon-Mannello Scale , a amostra constituiu-se de 17 I enfermeiros de um hospital universitário do Estado de São Paulo. Os resultados evidenciaram que mais da metade da amostra (52,4\%) possui experiência profissional com alcoolistas, sendo estes percebidos pelos participantes, como uma pessoa infeliz, solitária, sensível, Que duvida de seu próprio valor e apresenta severas dificuldades emocionais. Concluiu-se que as atitudes desses enfermeiros frente às características pessoais do paciente alcoolista tendem a ser positivas e sugere-se Que maior atenção seja dada ao treinamento desse profissional para reconhecimento e abordagem do alcoolista em hospital geral.

Descritores: Atitudes do pessoal de saúde; Enfermeiro; Alcoolismo.

\section{ABSTRACT}

The purpose of this exploratory study was to discover nurses' attitudes towards the perceptions of personal characteristics of alcoholics. Nurses' attitudes were measuared using the Seaman-Manello Scale, the sample consisted of 17I nurses who work in a university general hospital located in the State of São Paulo, Brazil. The results evidenced that more than half of the sample (52.4\%) had a professional experience with alcoholics. Nurses see the alcoholic patients as unhappy, lonely, sensitive people, who doubt their own value and have serious emotional problems. It is concluded that nurses' attitudes toward personal characteristics of alcoholic patients tend to be positive and suggests greater attention to professional training in recognition and approach of the alcoholic in general hospitals.

Key words: Attitude of health personnel; Nurse; Alcoholism.

\section{RESUMEN}

El objetivo de este estudio exploratorio fue verificar las actitudes de enfermeros de un hospital general ante las caracteristicas personales del alcohólico. Esta investigación fue realizada con una muestra de 171 enfermeros de un hospital universitario del Estado de São Paulo, Brasil. Los resultados evidenciaron que mas de la mitad de la muestra $(52,6 \%)$ tiene experiencia profisional con los alcohólicos, las enfermeras ven los alcohólicos como personas infelices, solitarias, sensitivas Que dudan de su propio valor y tienen serias dificultades emocionales. Se concluye que las atitudes de las enfermeras son positivas y que mayor atención debe ser dada a el treinamiento desto profesional para el reconocimiento y abordaje del alcoholico en el hospital general

Descriptores: Actitud del personal de salud; Enfermero; Alcoholismo

\footnotetext{
AUTOR CORRESPONDENTE Divane de Vargas. Av. Enéas Carvalho de Aguiar, 419/244. CEP 054403-000. São Paulo, SP.

E-mail: vargas@usp.br
} 


\section{INTRODUÇÃO}

Até o início deste século, o Brasil não dispunha de uma política Que contemplasse o planejamento de ações voltadas para atenção às pessoas Que consomem álcool e outras drogas. Em março de 2003, diante do reconhecimento da ausência do estado no enfrentamento dessa problemática e da constatação de Que tal uso tomou proporção de grave problema de saúde pública no País, com ressonância nos diversos segmentos da sociedade, pela relação comprovada entre consumo e agravos sociais Que dele decorrem ou Que o reforçam foi implantada a política do Ministério da Saúde para a atenção integral a usuários de álcool e outras drogas ${ }^{(1)}$.

De acordo com essa política, a assistência a usuários de álcool deve ser oferecida em todos os níveis de atenção, privilegiando os cuidados em dispositivos extra-hospitalares, como os Centro de Atenção Psicossocial para Álcool e Drogas (CAPSad), devendo também estar inserida na atuação do Programa de Saúde da Família, o programa de Agentes Comunitários de Saúde e da Rede Básica de Saúde. Ainda, segundo a política ${ }^{(1)}$, os casos de maior gravidade, como os Quadros de intoxicação ou abstinência graves e outros transtornos clínicos e psiquiátricos agudos devem ser acolhidos em dispositivos de saúde de maior complexidade, tais como: as emergências médicas e psiQuiátricas e os hospitais gerais.

No Que se refere ao atendimento dessa população no âmbito dos hospitais gerais, em 2005, o governo por meio da Portaria (PT GM 1.612/05) ${ }^{(2)}$ normatizou mecanismos de financiamento de leitos de hospital geral para usuários de álcool e outras drogas. Dessa forma, se antes da proposição da política nacional para a atenção integral a usuários de álcool e outras drogas já se percebia o aumento do número de pacientes com problemas relacionados ao álcool e ao alcoolismo em unidades de internação e de emergência de hospitais gerais ${ }^{(3-4)}$. Com a implantação dessa política, esses serviços passaram a se constituir formalmente em locais estratégicos na rede de atenção psicossocial, para essa população, de forma Que cada vez mais os enfermeiros de hospital geral têm prestado assistência a essa clientela.

Quando um alcoólico é admitido em unidades de hospitais gerais um dos primeiros membros da equipe da unidade Que entra em contato com ele é o enfermeiro Que, além de responsabilizar-se pela maioria dos contatos iniciais com esse paciente na instituição, é responsável pelo planejamento de sua assistência do mesmo durante a internação, o Que por si só justificaria a realização de estudos sobre as atitudes desse profissional diante de tais pacientes. Segundo os autores ${ }^{(5)}$, as atitudes apresentadas por esse profissional nos primeiros contatos com o paciente podem afetar significativamente o curso subsequente do tratamento.

A revisão da literatura vem evidenciando que os enfermeiros de serviços de saúde, consideram cuidar de pessoas com problemas relacionados ao álcool e outras drogas, como algo difícil e desagradável, com um predomínio de atitudes negativas frente à Questão $^{(4,6-10)}$. Pesquisa ${ }^{(6)}$ com o objetivo de verificar as atitudes de enfermeiros de hospital geral com relação à satisfação em trabalhar com pacientes alcoolistas, encontrou Que, embora sejam unânimes em considerar o hospital como um local adequado para o atendimento dessa clientela, sentiam-se desconfortáveis para trabalhar com os mesmos e evitavam abordar o problema temendo reações agressivas do paciente.
Estudo $^{(7)}$ realizado para verificar as concepções de enfermeiros de hospital geral frente ao paciente alcoolista, constatou Que este é concebido como desobediente, Que não gosta de ser como é, com dúvidas Quanto à sua capacidade para enfrentar os problemas. Outro estudo ${ }^{(8)}$ envolvendo atitudes, concepções e crenças de enfermeiros com relação ao alcoolista constatou Que os enfermeiros concebiam o alcoolista, como um indivíduo dependente, repetitivo e com baixa probabilidade de recuperação. Enquanto outra pesquisa $^{(9)}$ evidenciou Que os enfermeiros consideravam o alcoolista como uma pessoa sensível, com complexo de inferioridade e constatou Que os sujeitos do estudo apresentavam a tendência de ver o alcoolista como pessoa Que tem sua saúde mental prejudicada.

De modo geral, a análise da literatura sobre a temática evidencia o predomínio de atitudes negativas dos enfermeiros frente ao alcoolismo e ao alcoolista, pois, embora considerem o alcoolismo uma doença Que precisa de tratamento, o alcoolista um doente e o hospital geral como um local adequado para o tratamento desses indivíduos, ainda é possível encontrar significativo contingente de profissionais Que atribuem ao alcoolismo a vontade do próprio paciente ${ }^{(8,10)}$, predominando a insatisfação desses profissionais Quando precisam trabalhar com essa clientela ${ }^{(6)}$, apesar de se sentirem capazes de cuidar dela ${ }^{(10)}$.

Assim, considerando que a atual política do Ministério da Saúde para a atenção integral a usuários de álcool e outras drogas( ${ }^{(1)}$ estabelece o hospital geral, como um dos locais estratégicos para atendimento dessa população; considerando Que o enfermeiro desses serviços tende, cada vez mais se deparar com situações Que envolvem o uso do álcool e o alcoolismo e tendo em vista Que as atitudes apresentadas por esse profissional, podem influenciar no andamento do tratamento do alcoolista. Este estudo objetivou identificar as atitudes de enfermeiros de um hospital geral, frente algumas características pessoais do paciente alcoolista.

Mesmo amplamente estudado, o termo atitude ainda não possui uma definição precisa, o Que talvez explique o fato de, nas últimas décadas, numerosas definições terem sido propostas por vários autores. No entanto, parece ser consenso na literatura Que uma atitude seria uma predisposição adeuirida e duradoura para agir sempre do mesmo modo, diante de uma determinada classe de objetos ou um persistente estado mental e/ou neural de prontidão para reagir diante de certa classe de objetos, não como eles são mas, sim, como são concebidos ${ }^{(1)}$. Além disso, existem duas correntes de explicação para a constituição de uma atitude, a Que atribui mais de um componente em sua constituição - definição multidimensional - e a Que defende serem as atitudes constituídas por um único componente - definição unidimensional. Nas concepções multidimensionais, as definições de atitudes integram três componentes: o cognitivo, o afetivo e o comportamental ${ }^{(12)}$.

O componente afetivo é o único característico das atitudes sociais $^{(13)}$, sendo considerado o mais nitidamente característico das atitudes e é justamente o que difere as atitudes das crenças e opiniões Que embora, muitas vezes, se integrem em uma atitude e suscitem um afeto positivo ou negativo em relação a um objeto, predispondo à ação, não são necessariamente impregnados de conotação afetiva ${ }^{(13)}$. Para haver uma atitude em relação a um objeto, é necessária alguma representação cognitiva desse objeto. Assim, para Que haja uma carga afetiva pró ou contra um objeto social definido, faz-se mister uma representação cognitiva desse mesmo 
objeto. As crenças e demais comportamentos cognitivos relativos ao objeto de uma atitude constituem o componente cognitivo da atitude. Pessoas Que exibem atitudes preconceituosas, por exemplo, têm uma série de cognições a respeito do grupo, Que é objeto de sua discriminação ${ }^{(14)}$. Por último o componente comportamental ou comportamento conativo, refere-se à ação, à prontidão para reagir frente ao estímulo atitudinal; revela uma tendência do indivíduo em um movimento ou ação na direção do objeto de atitude. Esse comportamento pode ser verbal e não-verbal ${ }^{(15)}$. De acordo com os estudiosos do assunto ${ }^{(12)}$, é preciso entender Que as atitudes envolvem o Que as pessoas pensam, sentem e como gostariam de se comportar em relação ao objeto atitudinal, essa concepção define uma atitude, como sendo multidimensional, pois envolve três componentes: afetivo, cognitivo e comportamental.

\section{MÉTODO}

Trata-se de um estudo exploratório descritivo de abordagem psicométrica sobre as atitudes de um grupo de enfermeiros de hospital geral frente às características pessoais do paciente alcoolista. A psicometria é o termo utilizado ao estudo das medidas das ciências do comportamento, segue os princípios da teoria da medida em geral, Que buscam desenvolver uma discussão epistemológica para descrever fenômenos naturais, utilizando o símbolo matemático, o número ${ }^{(16)}$

A amostra do estudo constituiu-se de 17 I enfermeiros alocados em 18 unidades de internação de um hospital geral de caráter universitário de Ribeirão Preto, SP. Os critérios de inclusão na amostra foram aceitar participar do estudo e estar desempenhando a função de enfermeiro no momento da coleta.

$\mathrm{O}$ instrumento de coleta de dados foi a subescala IV da Escala The Seaman Mannello Nurse's attitudes toward alcohol and alcoholism Scale ${ }^{(17)}$, Que mensura as atitudes relacionadas à percepção das características pessoais do alcoolista" Neste estudo, a Subescala IV utilizada é composta de seis itens (Figura I), Que podem ser respondidos em uma escala do tipo likert de I a 5 pontos; e 1 representa completo desacordo com o item, e 5, representa completo acordo. Com a escala de atitudes, aplicou-se um Questionário com informações sociodemográficas dos participantes (idade, sexo, cargo), além de uma Questão a respeito da experiência profissional com alcoolistas.

Os instrumentos de coleta de dados foram entregues aos participantes em suas unidades de trabalho em envelopes lacrados e solicitou-se Que os Questionários não fossem identificados, a fim de garantir sua privacidade. O Questionário levou, Quase, 30 minutos para ser respondido e foram inclusas as instruções para o preenchimento, bem como o Termo de Consentimento Esclarecido.

Para análise dos dados, construiu-se um banco de dados no EPINFO, programa da Organização Mundial da Saúde (OMS), de domínio público, Que possibilitou realizar uma análise estatística descritiva das informações sociodemográficas da população estudada, bem como das respostas dadas aos itens da subescala IV, percepção das características pessoais do alcoolista. Nessa última, atribuiu-se um e dois pontos para categorias de respostas desfavoráveis (desacordo e total desacordo) ao item; três para categorias intermediárias (indiferente) e Quatro e cinco pontos para categorias favoráveis (acordo e total acordo).

O primeiro passo para a análise dos resultados consistiu na determinação do ponto médio dos escores Que poderiam ser obtidos em cada um dos itens Que compunham o instrumento, bem como na subescala em sua totalidade. Para obtenção desses valores, realizou-se a soma dos escores mínimo e máximo Que poderiam ser obtidos, em cada um dos itens (I e 5 pontos), bem como na subescala total (6 e 30 pontos). O produto da soma dos valores dos escores mínimos e máximos Que poderiam ser obtidos, divididos por 2, resultou no ponto médio dos escores da subescala igual a 18 e de cada um dos itens igual a 3 . Esses valores foram considerados como ponto de corte para interpretação das atitudes dos sujeitos, frente às características pessoais do paciente alcoolista.

Após, os pontos de corte serem determinados, procedeu-se a verificação das médias de escore obtidas pela amostra do estudo em cada item separadamente. $\mathrm{O}$ mesmo processo foi realizado para obtenção da média de escore dos sujeitos na Subescala em sua totalidade. Identificadas as médias obtidas dos escores pelos sujeitos em cada um dos seis itens e na Subescala total, o passo seguinte consistiu na interpretação dos resultados obtidos segundo as definições operacionais propostas pelas autoras da escala. Dessa forma, escores inferiores ao ponto médio da Subescala (18) e de cada um dos itens (3), foram considerados indicativos de atitude negativa, enquanto os escores superiores a esse valor foram

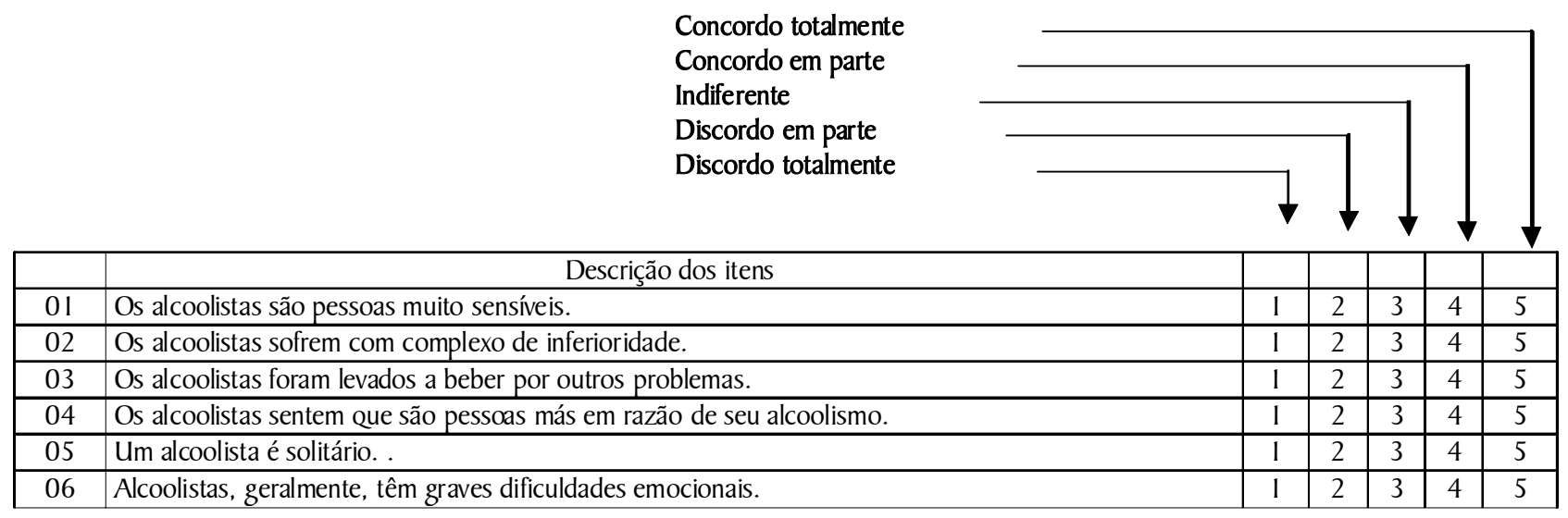

Figura 1. Apresentação dos itens Que compõem a subescala IV, "Percepção das características pessoais do alcoolista" e das opções de resposta. 
interpretados, como indicativos de atitude positiva.

Os aspectos éticos observados na realização desta pesQuisa foram a aprovação do projeto pelo Comitê de Ética em Pesquisa do Hospital das Clínicas da Faculdade de Medicina de Ribeirão Preto da Universidade de São Paulo sob número 576100, e a assinatura do Termo de Consentimento Livre Esclarecido pelos sujeitos Que participaram do estudo.

Conforme as autoras do instrumento ${ }^{(17)}$, enfermeiros com escore elevado na subescala IV "percepção das características pessoais do alcoolista", tendem a perceber o paciente alcoolista como uma pessoa infeliz, solitária, sensível Que duvida do seu próprio valor, com graves dificuldades emocionais. EnQuanto enfermeiros com escores baixos tendem a conceber o alcoolista, simplesmente, como um bebedor excessivo, sem nenhum tipo de problema psicológico.

\section{RESULTADOS}

\section{Caracterização dos sujeitos}

Os sujeitos do estudo, conforme ilustram os dados da Tabela I, caracterizaram-se como indivíduos do sexo feminino, com idade média de 32 anos, solteiros, formados entre 1 e 5 anos, em escolas públicas e sem formação em nível de pós-graduação. Quanto ao cargo exercido no serviço de enfermagem no momento da coleta, a maioria, denominou-se enfermeiro de turno. Do total da amostra, $52,4 \%$ revelaram já ter tido experiência profissional com alcoolistas em suas unidades de trabalho.

\section{Atitudes dos enfermeiros com relação à percepção das características pessoais do alcoolista.}

Considerando-se a escala de $\mathrm{I}$ a 5 , sendo I = limite desfavorável e $5=$ limite favorável, os resultados demonstraram que a atitude global dos enfermeiros do estudo foi favorável, visto Que o índice médio dos escores obtidos em cada um dos itens Que compõe a subescala IV manteve-se, com exceção do item 4, "os alcoolistas sentem Que são pessoas más devido seu alcoolismo", acima do ponto médio 3, conforme demonstram os dados da Tabela 2 .

A análise em conjunto dos escores obtidos pela amostra do estudo na Subescala IV resultou na média geral de 20,15. Este resultado é consistente com os verificados na análise individual dos itens e confirma a tendência de atitudes positivas dos enfermeiros frente às características pessoais do alcoolista, pois é superior àQuela estabelecida como ponto de corte para avaliação das atitudes (18).

Considerando as médias obtidas em cada um dos itens e a média geral obtida na Subescala IV, Que se apresentam acima dos pontos de corte, pode-se dizer, segundo a definição operacional estabelecida pelas autoras do instrumento Que esses sujeitos percebem o paciente alcoolista, como uma pessoa infeliz, solitária, sensível, Que duvida de seu próprio valor e com graves dificuldades emocionais.

O resultado foi consistente com os valores encontrados Quando se avalia a porcentagem de indivíduos Que se posicionou a favor ou contra os itens, pois, $46,5 \%$ dos enfermeiros concordam com o fato do alcoolista ser uma pessoa sensível, solitária; $51,5 \%$, com graves dificuldades emocionais $(82,2 \%)$ e que foram levados a beber por outros problemas. No entanto, avaliando as porcentagens de respostas ao item referente ao alcoolista sofrer com complexo de inferioridade, verifica-se Que esses enfermeiros parecem não estar
Tabela 1. Distribuição dos sujeitos do estudo, segundo as variáveis sociodemográficas, Ribeirão Preto, 2008. ( $n=171)$.

\begin{tabular}{|c|c|c|}
\hline \multirow{2}{*}{ VARIÁVEL } & \multicolumn{2}{|c|}{ FREQUÊNCIA } \\
\hline & $\mathrm{n}$ & $\%$ \\
\hline \multicolumn{3}{|l|}{ Sexo } \\
\hline Masculino & 21 & 12,3 \\
\hline Feninino & 150 & 87,7 \\
\hline \multicolumn{3}{|l|}{ Idade } \\
\hline 22 a 30 anos & 59 & 35,3 \\
\hline 31 a 40 anos & 66 & 39,5 \\
\hline 41 a 50 anos & 39 & 23,4 \\
\hline 51 anos ou mais & 03 & 1,8 \\
\hline \multicolumn{3}{|l|}{ Estado civil } \\
\hline Solteiro & 86 & 50,3 \\
\hline Casado & 77 & 45,0 \\
\hline Outros & 8 & 4,7 \\
\hline \multicolumn{3}{|l|}{ Tempo de formação } \\
\hline 01 a 05 anos & 77 & 45,5 \\
\hline 06 a 10 anos & 42 & 24,9 \\
\hline 11 a 15 anos & 18 & 10,7 \\
\hline 16 a 20 anos & 14 & 8,3 \\
\hline Mais de 20 anos & 18 & 10,6 \\
\hline \multicolumn{3}{|l|}{ Local de formação } \\
\hline Escola Pública & 94 & 55 \\
\hline Escola Privada & 77 & 45 \\
\hline \multicolumn{3}{|l|}{ Pós-graduação } \\
\hline Sim & 52 & 30,4 \\
\hline Não & 119 & 69,6 \\
\hline \multicolumn{3}{|c|}{ Experiência profissional com alcoolistas } \\
\hline $\operatorname{Sim}$ & 89 & 52,4 \\
\hline Não & 75 & 47,6 \\
\hline \multicolumn{3}{|l|}{ Cargo } \\
\hline Diretora de Seção & 05 & 2,9 \\
\hline Enfermeiro chefe & 15 & 8,8 \\
\hline Enfo encarregado & 02 & 1,2 \\
\hline Enfermeiro de turno & 149 & 87,1 \\
\hline
\end{tabular}

bem certos sobre o fato, tendo em vista Que mais da metade da amostra colocou-se em categorias intermediárias, sem acordo ou desacordo com o item. Situação semelhante foi encontrada Quando precisaram se manifestar frente ao item Que avalia se os enfermeiros acreditam Que o alcoolista sente-se uma pessoa má, em razão de seu problema. Nesse item, o percentual de enfermeiros sem opinião formada atingiu $37,5 \%$, seguido de um percentual bem próximo a esse $36,9 \%$ Que discordava do fato do alcoolista sentir-se uma má pessoa.

\section{DISCUSSÃO}

A análise dos resultados confirmou o pressuposto inicial deste estudo que apontava Que o enfermeiro de hospital geral tem tido cada vez maior contato com pacientes alcoolistas, pois, mais da metade dos sujeitos do estudo revelou ter experiência profissional 
Tabela 2. Apresentação da média de escores obtidos pela amostra do estudo na Subescala IV, percepção das características pessoais do alcoolista, Ribeirão Preto, 2008.

\begin{tabular}{clcccc}
\hline \multicolumn{1}{c}{ Item } & $\begin{array}{c}\text { Escore } \\
\text { Mínimo }\end{array}$ & $\begin{array}{c}\text { Escore } \\
\text { Maximo }\end{array}$ & Média & DP \\
\hline $1 \quad \begin{array}{l}\text { Os alcoolistas foram levados a beber } \\
\text { por outros problemas. }\end{array}$ & 1 & 5 & 3,26 & 0,91 \\
$2 \begin{array}{l}\text { Os alcoolistas sofrem com complexo } \\
\text { de inferioridade. }\end{array}$ & 1 & 5 & 3,76 & 0,93 \\
$3 \quad \begin{array}{l}\text { Os alcoolistas são pessoas muito } \\
\text { sensíveis. }\end{array}$ & 1 & 5 & 3,30 & 0,98 \\
\hline $\begin{array}{l}\text { Os alcoolistas sentem que são pessoas } \\
\text { más em razão de seu alcoolismo. }\end{array}$ & 1 & 5 & 2,86 & 0,89 \\
\hline $\begin{array}{l}\text { Alcoolistas, geralmente, têm graves } \\
\text { dificuldades emocionais. }\end{array}$ & 1 & 5 & 3,09 & 0,95 \\
\hline
\end{tabular}

com esse paciente em seus locais de trabalho. No entanto, chamou atenção o fato do elevado percentual $(47,6 \%)$ dos sujeitos Que negaram tal experiência. Talvez isso se explieue, pela dificuldade dos profissionais de saúde para identificar e encaminhar pacientes com problemas relacionados ao álcool e outras drogas para tratamento especializado Quando se deparam com esses nos serviços de saúde.

Por sua vez, esta dificuldade pode ser atribuída, conforme relatado na literatura ${ }^{(4,18-20)}$, ao fato de Que pouco ou nenhum preparo tem sido assegurado aos profissionais de saúde, dentre eles, os enfermeiros durante a formação para o reconhecimento, abordagem e tratamento de pacientes Que apresentam problemas relacionados ao álcool e outras drogas. A esse respeito, pesquisa ${ }^{(21)}$ realizada com médicos e enfermeiros nos Estados Unidos da América constatou Que dois terços dos entrevistados sentiam-se despreparados para reconhecer e abordar o problema do uso do álcool e do alcoolismo com seus pacientes. Consistente com os resultados de outros estudos ${ }^{(7,9)}$, esta pesquisa revelou Que os enfermeiros tendem a conceber o alcoolista como pessoas infelizes, solitárias, sensíveis, Que duvidam de seu próprio valor e com sérias dificuldades emocionais. O resultado indicou uma tendência de atitudes positivas, pois contrapôs-se à concepção de Que o alcoolista é simplesmente um bebedor excessivo sem nenhum problema psicológico.

Ao conceberem o alcoolista como um indivíduo com problemas psicológicos, pode-se inferir Que esses enfermeiros tendem a rejeitar a explicação moral para o alcoolismo Que reduz o problema à vontade do próprio paciente, Que, também, é considerado responsável por interromper o uso do álcool, culpando-o em última análise por seus problemas de saúde. A constatação de Que o alcoolista é concebido por esses enfermeiros, como uma pessoa com problemas psicológicos, indicando a existência de atitudes positivas é reforçada pela concepção de Que se trata de pessoa com graves dificuldades emocionais. Este resultado é corroborado por outros estudos ${ }^{(22)}$, em Que os enfermeiros concebiam o alcoolista como uma pessoa psicologicamente abalada. Ver o alcoolista, como uma pessoa psicologicamente abalada, modifica, ao menos parcialmente, a concepção de Que ele não está doente porQue Quer, o Que certamente repercute no cuidado a lhe ser dispensado, tendo em vista Que, segundo a literatura(23), Quando existe a associação entre a doença e a responsabilidade pela situação clínica do paciente pelo enfermeiro Que a mesma pode influenciar negativamente no relacionamento enfermeiropaciente e, consequentemente, no cuidado de enfermagem.

Perceber o alcoolista como uma pessoa sensível, com problemas emocionais, certamente, facilita o estabelecimento de um relacionamento interpessoal, levando o profissional a reconhecer no alcoolista uma pessoa Que precisa de ajuda, o Que é considerado um fator importante, Quando se trata de cuidar desse tipo de paciente, pois se o profissional não sentir no alcoolista alguém Que mesmo, muitas vezes, recusando, precisa de sua ajuda, dificilmente cuidará com eficiência(18).

Além de conceber o alcoolista como alguém Que está precisando de ajuda, é importante também Que o enfermeiro reconheça Que a hospitalização pode constituir-se em um momento de crise para o paciente, já Que, nesse período, ele poderá estar passando por uma fase de estresse físico e psicológico, causado pela abstinência, além de poder ter sua doença evidenciada pela primeira vez. Dessa forma, ao estabelecer contato com o alcoolista durante a internação, o enfermeiro precisa vislumbrar Que o paciente poderá estar em extremo sofrimento psíquico, o Que exigirá que lance mão de suas habilidades de relacionamento interpessoal para atuação com ele ${ }^{(18,22)}$, reconhecendo a internação como um momento de crise, buscando, assim, formas adequadas de abordagem com esse paciente, o Que certamente será mais fácil, caso o profissional mostre-se sensível à situação do mesmo.

$\mathrm{Na}$ análise de cada um dos seis itens separadamente, a menor média $(2,86)$ foi encontrada no item 4 Que avalia as atitudes dos enfermeiros no Que se refere ao alcoolista sentir-se uma pessoa má, em razão de seu problema, indicando que esses enfermeiros não estão bem certos sobre essa Questão. Este resultado pode denotar uma tendência de atitude negativa, pois ao conceber Que o alcoolista não se sente uma pessoa má e Que não se culpa pelo seu problema, podem estar atribuindo a esse paciente a indiferença diante de sua doença. Esta atitude parece estar impregnada pela explicação do alcoolismo, como um desvio moral, com a compreensão de Que um adicto só valoriza a sustância Que utiliza ${ }^{(9)}$.

Esse dado é consistente com o evidenciado em outros estudos ${ }^{(22)}$, nos Quais o alcoolista era concebido pelos enfermeiros, como uma pessoa Que bebe sem se importar com o Que acontecerá depois, revelando concepções Que podem ser compreendidas, como inconsequência e irresponsabilidade. Atitude essa que parece, no entanto, não encontrar respaldo na literatura sobre o tema ${ }^{(24)}$ Que aponta Que existem sentimentos desconfortáveis vivenciados pelo alcoolista, tais como: culpa, arrependimento e mágoa, refletidos em sintomas de depressão, necessidade de isolamento e autopunição. De modo geral, os alcoolistas demonstram insatisfação consigo mesmo e com a vida, sentindo-se frustrados.

Na percepção dos enfermeiros do estudo, o alcoolista é um solitário, resultado corroborado com outros estudos Que avaliaram as atitudes diante das repercussões do alcoolismo na vida do 
indivíduo, nos Quais os enfermeiros percebiam o alcoolista, como um indivíduo Que acaba só(7-9,22). Esse resultado pode estar fundamentado na percepção da relação conflituosa entre o alcoolista e sua família, acarretando na deterioração das relações familiares, já Que QualQuer pessoa Que interfira entre o alcoolista e o álcool terá de enfrentar a fúria pela separação entre o bebedor e o objeto de desejo, o álcool, deterioração essa Que extrapola para os desajustes sociais, em um crescente tal Que a maioria dos alcoolistas acaba só, ou porque se isola, ou porque é abandonada ${ }^{(25)}$.

Os enfermeiros da pesquisa concordaram com o fato de que o alcoolista é levado a beber por outros problemas. Este resultado é consistente com outros estudos ${ }^{(22)}$ Que evidenciaram Que, na concepção desses profissionais, fatores psicosocioculturais como, desemprego, dificuldades financeiras, insatisfação com a vida, problemas conjugais, desajustes familiares, busca de soluções para problemas afetivos e fuga dos problemas foram apontados como causas do alcoolismo. $\mathrm{O}$ autor $^{(22)}$ aponta Que isso pode remeter à carência de conhecimento, tendo em vista Que esses fatores podem levar o indivíduo a beber; no entanto, podem ser vistos como agentes etiológicos para o alcoolismo. Assim, o comportamento do beber e os problemas aos Quais ele está associado, são determinados por fatores múltiplos interatuantes, relacionados tanto ao indivíduo como a seu meio ambiente. Este comportamento não pode ser compreendido totalmente com base nos problemas cotidianos da vida e no meio ambiente isoladamente mas só como uma interação entre uma variedade de fatores biopsicossociais ${ }^{(26)}$.

Apesar dos resultados evidenciarem o predomínio de atitudes positivas desses enfermeiros no Que se refere às características pessoais do paciente alcoolista,segundo o instrumento utilizado, os participantes demonstraram dúvida Quanto ao fato do alcoolista sentir-se uma pessoa má e com complexo de inferioriade. Os resultados parecem indicar a existência de ambivalência nas atitudes dos enfermeiros frente às Questões Que envolvem o álcool e o alcoolista, pois, se de um lado, acreditam Que essas pessoas são sensíveis e psicologicamente abaladas, de outro, parecem não ver nesses indivíduos alguém Que se interessa por seu problema, pois não se sentem maus ou culpados pelo mesmo. Esta ambivalência nas atitudes dos enfermeiros, talvez se explieue, pelo fato, do modelo moral de explicação para o alcoolismo, ainda exercer forte influência nas concepções e atitudes de enfermeiros e profissionais da saúde de um modo geral ${ }^{(22)}$ o Que pode gerar atitudes ambivalentes no enfermeiro ${ }^{(10)}$.

No entanto, ao conceber Que os alcoolistas bebem em decorrência de problemas, são sensíveis, solitários e com problemas emocionais, não significa Que os mesmos enfermeiros não tenham outras atitudes Que reflitam valores morais. Em estudo anterior ${ }^{(18)}$ utilizando outra subescala do mesmo instrumento, evidenciou-se Que os enfermeiros apresentavam esse tipo de atitude com relação ao consumo do álcool.

A respeito das características pessoais do alcoolista, autores ${ }^{(28)}$, discorrendo sobre uma possível personalidade alcoólica apontam Que as pesQuisas não confirmam a crença de Que exista uma personalidade central comum ou um conjunto de defesas fortemente estabelecidas Que seja característico de pessoas Que sofrem de abuso de álcool. Esses autores ${ }^{(28)}$ chamam atenção, ainda, para os efeitos negativos de se considerar Que existe uma 'personalidade do alcoolista', já Que este pode ser compreendido e rotulado em função destas características e considerado como diferente do resto da população. Assim, esses apontamentos devem ser considerados ao se utilizar os dados dessa pesquisa.

No entanto, observo que o presente estudo possui várias limitações, dentre elas, foi realizado com uma amostra de um único hospital e apresenta os resultados obtidos em apenas uma subescala de um instrumento específico, portanto, não podem ser generalizados, pois, fornecem informações sobre apenas seis atitudes referentes ao objeto em Questão. Apesar dessas limitações, os resultados aQui apresentados contribuem para o conhecimento a respeito da temática atitude de enfermeiros frente às Questões relacionadas ao álcool e ao alcoolismo, em especial, sobre as percepções das características pessoais do alcoolista, sobretudo pela carência de estudos publicados na literatura nacional sobre a Questão.

\section{CONCLUSÃO}

As atitudes dos enfermeiros frente às características pessoais dos alcoolistas tendem a positividade, pois estes são percebidos como uma pessoa sensível, sozinha e com graves dificuldades emocionais. Esta atitude pode contribuir para Que o enfermeiro reconheça no alcoolista alguém Que está doente e precisa de ajuda e na internação em hospital geral um momento de crise e passível da intervenção do enfermeiro, o Que pode favorecer o estabelecimento do relacionamento interpessoal enfermeiro versus paciente alcoolista.

Percentual significativo de enfermeiros negou possuir experiência profissional com alcoolistas no âmbito do hospital geral, esse resultado pode ser um indicativo de Que os enfermeiros não estejam preparados para reconhecer pacientes com essa problemática, sobretudo Quando se analisam os dados relativos à prevalência de internações dessa população. Isso pode indicar falha na formação desses profissionais Que mesmo em contato com esses indivíduos têm dificuldade para reconhecê-los, ou mesmo, associar seu problema de saúde com o uso de álcool e alcoolismo.

Existe a necessidade de um maior investimento no preparo desses profissionais para o enfrentamento dessa problemática, Quer no decorrer da educação formal, Quer por meio de treinamentos em serviço e educação permanente. Segundo $\operatorname{estudos}^{(4)}$ realizados, pacientes com problemas relacionados ao álcool e ao alcoolismo, Quando internados em hospital geral podem ser beneficiados, se forem identificados e abordados adeouadamente. Dessa forma, o enfermeiro de hospital geral encontra-se em uma posição privilegiada para intervir nesse Quadro, contribuindo significativamente para prevenção, detecção e tratamento dos problemas relacionados ao álcool e ao alcoolismo, bem como para a reabilitação do paciente alcoolista.

\section{REFERÊNCIAS}

1. Ministério da Saúde (BR). A Política do Ministério da Saúde para a Atenção Integral a Usuários de Álcool e outras Drogas. Brasília: Ministério da Saúde; 2003.
2. Ministério da Saúde (BR). Portaria/GM no 1612, de 9 de setembro de 2005 - Define normas de funcionamento e credenciamento/habilitação dos Serviços Hospitalares de 
Referência para a Atenção Integral aos Usuários de Álcool e outras Drogas. Brasília: Ministério da Saúde;2005.

3. Noto AR, Moura YG, Nappo AS, Galduróz JCF, Carline EA. Internações por transtornos mentais e de comportamento decorrentes de substâncias psicoativas: um estudo epidemiológico nacional do período de 1988 a 1999. I Bras Psie 2002; 5 I (2): I I3-21.

4. Lopez-Bushnell K, Fassler C. Nursing Care of Hospitalized Medical Patients with Addictions. I Addictions Nurs 2004; 15 : 177-82.

5. Travelbee I. Interpersonal aspects of nursing. Philadelphia: Davis; 1971.

6. Vargas D, Labate RC. Trabalhar com pacientes alcoolistas: satisfação de enfermeiros de hospital geral. Rev Gaúcha Enferm 2005; 26(2): 252-60.

7. Lucca DM , Vargas D. As concepções de enfermeiros de hospital geral frente às Questões relacionadas ao álcool e ao alcoolismo. Enferm Bras 2006; 5(4): 260-7.

8. Vargas D, Luis MAV. Alcohol, alcoholism and alcohol addicts: conceptions and attitudes of nurses from district basic health centers. Rev Latino-am Enfermagem 2008; 16(esp): 543-50.

9. Navarrete PR, Luis. MAV. Actitude de la enfermera de um complejo hospitalario em relacion al paciente alcoholico. Rev Latino-am Enfermagem 2004; 12(esp): 420-6.

10. Vargas D. Atitudes de enfermeiros frente às habilidades de identificação para ajudar o paciente alcoolista. Rev Bras Enferm 2008; 63(2): 190-5.

11. Biblioteca Virtual em Saúde. Descritores em ciências da Saúde. São Paulo; 2007. [citado em 2008 Jan 15]. Disponível em: http://decs.bvs.br/.

12. Triadis HC. Attitude and attitude change. New York: John Wiley, 1971.

13. Fishbein M, Ajzen I. Belief, attitude, intention and behavior: introduction to theory and research. Boston: Addison-Wesley Publishing; 1975.

14. Rodrigues A. Psicologia social. $12^{\mathrm{a}}$ ed. Petropolis: Vozes; 1978.

15. Whedall K. Comportamento social: problemas fundamentais $\mathrm{e}$ importância social. Rio de Janeiro: Zahar; 1976.

16. Pasquali L. Psicometria: teoria dos testes na psicologia e na educação. Petrópolis: Vozes; 2003

17. Seaman J, Mannello T. Nurses' Attitudes Toward for Alcohol and Alcoholism- the Seaman Mannello Scale. Bethesda: National Institute on Abuse and Alcoholism; 1978.

18. Vargas D, Labate RC. Atitude de enfermeiros de hospital geral frente ao uso do álcool e ao alcoolismo. Rev Bras Enferm 2006; 59(1): 47-51.

19. Cruz MS, Silva Filho JF. A formação de profissionais para a assistência de usuários de drogas e a constituição de um novo habitus de cuidado. J Bras Psie 2005;54(2): I20-6.

20. Ramos LH, Pillon SC, Cavalcante MBG, Luiz MV, Padredi F, Laranjeira RR. O ensino sobre dependência Química em cursos de graduação em enfermagem no Brasil, 1998. Acta Paul Enferm 2001; 14(3): 35-43.

21. Valente CM, Sobal J, Muncie HL Ir, Levine DM, Antlitz AM. Health promotion: physicians' beliefs, attitudes, and practices. Am J Prev Med 2002;2(2):82-8.

22. Vargas D, Luis MAV. Construção e validação de uma escala de atitudes frente ao álcool, ao alcoolismo e ao alcoolista. Rev Latino-am Enfermagem 2008; 16(5): 895-2.

23. Olse DP. When the patient causes the problem: the effectt of patient responsibility on the nurse-patient relationship. I Adv Nurs 1997; 26: 515-22.

24. Diniz SA, Rufino MC. Influencia das crenças do enfermeiro na comunicação com o alcoolista. Rev Latino-am Enfermagem 1996; 4(esp): 17-23.

25. Assunção NA. Alcoolismo e ensino de enfermagem: convergências e divergências entre o discurso e a prática. Pelotas: Universitária/UFPel; 2000.

26. Edwards GE, Marshall J, Cook CH. O tratamento do alcoolismo: Um guia para profissionais da saúde. $3^{a}$ ed. Porto Alegre: Artes Médicas; 1999.

27. Miller WR, Rollnick S. Entrevista motivacional: preparando as pessoas para a mudança de comportamentos adictivos. Porto Alegre: Artes Médicas; 2001. 